\title{
A Study of Difficulties and Approaches for Innovative Talents Training of Public Administration Undergraduates
}

\author{
Yanhan $\mathrm{Zhu}^{1}$ \& Juan $\mathrm{Wu}^{2}$ \\ ${ }^{1}$ School of Political Science and Public Administration, Southwest University, Chongqing 400715, China \\ ${ }^{2}$ Academic Affairs Office, Southwest University, Chongqing 400715, China \\ Correspondence: Yanhan Zhu, Tiansheng Road, Beibei, Chongqing, 400715, China. E-mail: 85817872@qq.com
}

Received: July 22, $2014 \quad$ Accepted: September 7, $2014 \quad$ Online Published: September 20, 2014

doi:10.5539/hes.v4n5p75 URL: http://dx.doi.org/10.5539/hes.v4n5p75

The research is sponsored by "the Teaching Reform Project of Southwest University" (Project grant No. 2013JY071).

\begin{abstract}
The innovation is the soul of one nation making progresses. To build an innovative country, we need to train more innovative talents who is capable of public administration. The innovative talents training of public administration undergraduate faces a lot of problems, such as the influences of traditional culture, the constraint of education ideology, the unclear definition of the specialty, the un-conspicuous specialty features, and the weak practice teaching. On the basis of the characteristics of innovative talents, this paper tries to explore the effective approaches for training innovative talents of public administration undergraduates.
\end{abstract}

Keywords: public administration, innovative talents, training

\section{Introduction}

"Improve the ability of independent innovation and build the innovative country." It is the core of the national development strategy and the key for improving the comprehensive state power. Adhere to the road of independent innovation with Chinese characteristics, and apply the "enhancing independent innovation ability" to all fields of the modern construction. To build an innovative country, talents are the basis and the guaranty. "National Long-Term Education Reform and Development Plan (2010-2020)" clearly points out that the higher education must highlight the requirements for training innovative scientific and technological talents, paying more attention to cultivating application talents.

Since the $80 \mathrm{~s}$ in $20^{\text {th }}$ century, with the social development and the transformation of government administration, the education and the training of public administration talents have received more attentions gradually. Social demands for public administration talents have been increasing. The public administration is an emerging specialty, being more practical, flexible, and personalized. This specialty is supposed to train specialized public administration talents who adapt themselves to China's social development and economic development, equipped with high comprehensive quality, innovation spirits, and innovation abilities. Therefore, the public administration undergraduate education should not be limited to the transfer of theoretical knowledge, but focus more on the cultivation of innovation spirits and innovation abilities. The graduates of public administration should grasp the current popular public affair organizations' operation modes in the world and be capable of predicting the future development trend of one organization. Considering the reform process currently in China, they can creatively provide public services and public goods. To study the training of the public administration undergraduate innovative talents has both important theoretical meanings and practical meanings for improving the quality of undergraduate teaching, implementing the reform of undergraduate education, and cultivating innovative talents.

\section{Difficulties in Front of Innovative Talents Training of Public Administration Undergraduates}

\subsection{Influences of Traditional Culture and Restraints of Educational Ideology}

The traditional culture is the main resistance factor as for the training of students' innovation abilities, because of its moderation thinking pattern and the emphasis on the harmony of human and nature. Some colleges and 
universities have still used the antiquated traditional education ideology and the outdated approach, not completely or widely implementing the advanced scientific education ideology at all. Under the influences of the authority-oriented values, the education lacks of democracy and science. The teaching and the learning have been limited to the traditional rules and regulations. Students have no chance to show their personalities and creativity. The traditional culture contains students' spirits of exploration and innovation.

\subsection{Unclear Specialty Definition and Obscure Specialty Characteristics}

Because the public administration covers a wide range of subject, some colleges and universities do not develop a definitive recognition to this specialty, resulting in unclear specialty definition and obscure specialty characteristics. Therefore, the professional training has not a specific target, and lacks of knowledge structure or knowledge levels. The expertise and the quality of public administration graduates are not prominent as much as possible. Students do not know what they will learn from the specialty, or what kind of jobs they will take after the graduation. Besides, the society does not understand the professional skills of the undergraduates of the public administration. The unclear specialty definition and training pattern in colleges and universities cause the disconnection of the public administration talents training from social demands. At present, the public administration specialty covers a wide range of courses, almost including all the core courses of the management specialty. The curriculum arrangement is scattered and loose, without unified curriculum arrangement criterion. Compared with other specialties, the public administration has no prominent professional characteristics and professional advantages.

\subsection{Weak Practice Teaching}

Generally speaking, the public administration has the problem of too much theoretical training but few theory-and-practice combined training. Students lack of practical awareness and operation abilities. First, the recognition to practice is insufficient and the practice is not emphasized in daily teaching. The practice is often a mere formality for both teachers and students. In addition, the practice part has no general planning or systematic process design, which causes the undergraduates' practice oversimplified. Second, the professional practice is usually in simple forms, due to the outdated contents. It emphasizes on professional theories instead of practical activities. The students of public administration specialty should not only grasp the theoretical knowledge of the specialty, but also master the abilities of practical operation, speaking, thinking, and judging. Therefore, on one hand, students should take effort to acquire specialty knowledge. On the other hand, they should frequently participate in social practice, practical research, and other practical activities. However, the existing training pattern of public administration talents emphasizes on the transfer of theoretical knowledge, ignoring the important role of practice.

\section{The Characteristics of Innovative Talents of Public Administration Undergraduates}

In terms of morals, knowledge, skills, and physical condition, the innovative talents usually possess these following characteristics: the noble sentiments and good morality; with a strong sense of curiosity, thirst for knowledge, and the spirit of entrepreneur; the indomitable willpower and the spirit of adventure, brave enough to break the old system; have abundant and extensive professional skills, and the ability of outstanding innovative practice; possess meticulous and rigorous scientific thinking, and the pragmatic scientific attitudes; have the excellent self-learning ability, the communication ability, and the teamwork ability, as well as the professional keen insight, judgment, and incisive critical thinking skills. In summary, it includes innovative thinking, innovative personality, and innovative practice.

\subsection{Innovative Thinking}

The innovative thinking is the key intellectual structure of the entire innovative activity. It is the core condition of the innovative talents. The innovative thinking mainly includes these aspects: lateral thinking and convergent thinking, divergent thinking, system thinking, horizontal thinking and vertical thinking, reverse thinking and positive thinking, etc. The innovative thinking is a complex, high-level, and unique information processing. The creativity studies agree that one person's innovative thinking ability can be assessed by the fluency, the flexibility, and the originality of his or her thinking activity. Therefore, in order to educate the undergraduates of the public administration with innovative thinking, we must focus on the fluency, the flexibility, and the originality of independent thinking.

\subsection{Innovative Personality}

It embodies the non-intellectual factor of the innovative ability training. The innovative personality characteristics include these following aspects: the curiosity and the thirst for knowledge, independence, braveness, questioning and innovative spirits, strong will, and so on. Here, the curiosity and the strong will are 
the core, which play the basic and critical role in individuals' innovative activities. Innovative personality is non-intellectual factor. It is a more important quality than the intellectual factor among the innovative qualities, because the innovative personality is a trained habits and willing for innovation on the basis of people's innate qualities. The innovative personality is an inherent natural tendency of the innovative quality. The innovative personality is an innovative activity of inherent dynamic innovative mechanism. It is the accumulation of innovation awareness and innovation spirits in individuals' hearts. The innovative personality is the inherent power force for the formation of innovation capability.

\subsection{Innovative Practice}

The innovative practice is the action that the target actor takes by means of innovative thinking and innovative imagination, under the guidance of innovative goals. It is carried out by the target actor's external activity under the joint effects of actor's psychological activity and external influences. The result of practice can be both the materialized goods and the practice self and its effects. Innovative practice is the practical operation or the explicit form of innovation awareness, innovation thinking, and innovation ability. Only by applying to the innovative practice, can the innovative awareness, innovative thinking, and innovative ability produce practical social values. In order to train students with innovative ability, we must emphasize on the innovative practice. It is the core, in other words, it is the "application innovation". It means, on the basis of mastering theoretical knowledge and technical knowledge, to apply the knowledge to the study and the work in a flexible and innovative way, and to develop some innovative and practical results. The innovative practice training embodies the laws of the higher education fundamentally.

\section{The Approaches for Innovative Talents Training of Public Administrative Undergraduates}

\subsection{Create the Atmosphere of Innovation Culture, and Develop Students' Awareness of Innovation}

The innovation is the accumulation of the factors of practice, knowledge, and culture. The innovative culture and innovative atmosphere affect students' innovative awareness in a potential and subtle way. The specialty of public administration provides a variety of extra-curricular and colorful science and technology activities, creates a strong atmosphere of academic innovation, and cultivates the students with the quality of honoring innovation and pursuing the truth. The colleges should create the high-quality forum and provide chances for students meeting with academic masters, help students to appreciate the power of professionals, and know about the latest research fruits. Besides, the colleges can promote the formation and the improvement of academic feelings, academic literacy, and academic pursuits. Furthermore, the colleges can also build the platform for students' scientific and technological communication, and promote the communication by means of project process reports, and exchange of experiences. In addition, the colleges can introduce the scientific and technological competition to improve students' innovative spirits, practice abilities, and science and technology qualities.

\subsection{Take the Competency as the Basis and Achieve the Coordinative Development and Integrated Improvement of} Knowledge, Abilities, and Qualities

The public administration is a dynamic and developing discipline. In a sense, public administration is a kind of comprehensive work. The government departments need people who have better competency and higher overall quality and know well about policies. Therefore, the talents training of public administration must take the competency as the basis, promoting the students' coordinative development and comprehensive improvement of knowledge, abilities, and qualities. For the talents training of public administration, the competency includes these following factors: professional theories, professional skills, and professional practices. The public administration undergraduates must master these professional theories: the basic concepts and analytical methods of dialectical materialism and historical materialism; the public administration theories and analysis methods. The public administration undergraduates must acquire these professional skills: master the scientific analysis methods and skills, such as systematic analysis, social statistical analysis, survey analysis, and computer analysis. The public administration undergraduates must know about these professional practices: understand the social survey methods and can perform social practice activities independently. In the talents training practice of public administration, the professional theories, the professional skills, and the professional practice should be transformed into students' concrete abilities properly.

\subsection{The Teaching Contents Should Focus on Cross-Disciplinary and Inter-Penetration}

The public administration is a multi-disciplinary specialty, which takes administration management as the focus, and involves in economics, management, laws, and literature. Therefore, we must change the former "professionals-style" education. We should, on the basis of enhancing the professional theories from public management, economics, laws, sociology, social security, and public organization theory needed by the public 
administration discipline, increase the proportion of elective courses, and encourage students to make trans-major, trans-discipline, trans-college, and even trans-university course selection based on their interests and hobbies. By means of emphasizing on trans-disciplinary education, we can promote the cross-disciplinary and inter-penetration, stimulate students' innovative awareness and innovative inspiration, and train their thinking ability.

\subsection{The Teaching Methods Emphasize on the Exploration-and-Discovery Teaching Ideas}

In practical teaching, college teachers should make full use of case analysis, scenario simulation, management games, group discussions, and exchange of experiences, and perform discussion teaching, instructive teaching, and inspiration teaching around the central task of public management and administration management. They can invite government officials who have abundant practical experiences to provide case study courses. They can guide students step into the front field of public administration, and help them master the latest theoretical developments, and improve the ability of applying theories to practices. In the teaching process, teachers can adopt the "seminar" approach, which is very popular in western countries. By this way, teachers can fully mobilize the students' participation and initiatives, and help them to make in-depth and groundbreaking research on certain subject. College teachers can carry out the practice teaching based on practical application problems and achieve the combination of theory and reality. Help students to make practice innovative activities by groups. Train students with the practice ability of applying innovative thinking and innovative approach to solve practical problems. In these activities, students should keep keen insight to the practical problems, and can analyze and solve the problems correctly and effectively, predict the future of the products, and propose the innovative ways to solve problems properly.

\subsection{Establish the Group Mentoring System}

In order to develop the innovative talents training, the group mentoring system is an effective and feasible way. Although the traditional "one mentor in charge system" has the advantage of distinct responsibilities, this system is limited by one mentor's thinking pattern, limited knowledge reserve. In this system, the students usually develop a narrow vision, restricted thinking, and limited knowledge, which is no good for innovative talents training. In the group mentoring system, the mentors include: one dominant mentor, two associate mentors, a few of school mentors with different academic backgrounds, research fields, and knowledge structures, world famous scholars, experienced government experts or non-government experts from public organizations. It is the group of mentors that organize the class teaching and provide thesis directions together. With this group mentoring system, students can get mentoring from different mentors. The cross disciplinary and penetration can benefit the cultivation of public administration undergraduates' innovative abilities, triggering the birth of innovative thinking and innovative achievements.

\subsection{Establish the Scientific and Reasonable Teaching Evaluation and Incentive Mechanism}

To establish the scientific and reasonable teaching evaluation system and incentive mechanism is the most powerful system guaranty for training public administration undergraduates' innovative abilities. First of all, as for the teaching evaluation, teachers should build a set of comprehensive teaching evaluation system to assess students' exams, classroom performances, thinking abilities, cooperation and communication abilities, practice abilities, scientific research and innovation abilities, and make comprehensive and integrated assessments and evaluations, instead of taking the exam as the sole criterion to assess students' performances. Secondly, as for the incentive mechanism, schools can encourage students to participate in innovative activities through the creation of school innovative credits, innovation scholarships, and innovation program rewards. Meanwhile, schools can provide professional assistance and funds for students' innovative activities. In addition, the school can also establish the special reward for teachers' guidance and give teachers credits for their guidance. By this way, it will mobilize the teachers' enthusiasm for guiding students' innovative activities.

\subsection{Build the "Competency Based" Talents Training Mode}

The competency is an individual characteristic that can reflect the level of performance in a specific position or an organizational environment. The public administration specialty must establish the objectives of "competency based" talents training pattern, perform the overall design and reform of talents training from knowledge, techniques, and personality features. First of all, we should integrate and optimize the professional knowledge system. The "competency based" talents training pattern should take "updating knowledge, strengthening skills, and improving qualities" as the central objective, optimizing the teaching contents according to the professional positions, and adjusting the curriculum system and structure. Besides, we can lay stresses on the "specific industry related" courses, such as the social community management, an introduction to social work, the municipal management, the secretarial management, the local government study, the electronic government, and 
the management information systems. We should take these courses as the emphasis of the teaching reform. Secondly, we can strengthen the practice skill training. In addition to the emphasis on the construction of school teaching labs, the independent colleges should seek the support of neighboring government agencies and the enterprises, trying to expand various types of off-campus practice teaching platforms. Colleges can arrange for students to participate in internships in communities, government departments, and public institutions and Offer necessary practice directions and strengthen practice management. Improve students' language skills, adaptability, innovation abilities, and professional skills. Thirdly, we can train and develop students' personality characteristics. In order to effectively improve students' employment competency, teachers should establish the objectives of the specialty and accept the objectiveness of students' diversified personalities. Based on students' personality characteristics, teachers can adopt the interactive teaching approaches, such as the task-driven teaching, case study, group discussion, etc., to stimulate students' interests in the specialty and their inner motives,

\section{References}

Bao, K., \& Jiang, Y. (2012). An exploration on the systematic training practices for undergraduate innovative talents in colleges. Higher Education Forum, 10.

Chen, H. (2012). An investigation on the "ability-needs-combination-transformation" talents training mode for public administration management in colleges. Guangxi Education, 10.

Liu, B. (2013). The dilemma for the undergraduate training of the specialty of public administration and the countermeasures. Education and Vocation, 10.

Lin, Q., \& Cao, L. (2012). The empirical analysis of the public administration management undergraduate talent training situation. Journal of Shaanxi Academy of Governance, 26(4).

Liu, W., Wang, L., Cheng, X., \& Li, Y. (2010). Constitute an innovative platform, improve the process management, and train innovative talents. Higher Agricultural Education, 8.

Yue, X. (2011). Study on the behavior mode of innovative talents. Master Thesis of Zhengzhou University.

\section{Copyrights}

Copyright for this article is retained by the author(s), with first publication rights granted to the journal.

This is an open-access article distributed under the terms and conditions of the Creative Commons Attribution license (http://creativecommons.org/licenses/by/3.0/). 